\title{
HYPERCHOLESTEROLEMIA AND PREVENTION OF CARDIOVASCULAR DISEASES IN THE LIGHT OF PREVENTIVE MEDICAL EXAMINATIONS OF EMPLOYEES IN POLAND
}

\section{DANIEL ŚLIŻं,2, ANDRZEJ MARCINKIEWICZ³, DOMINIK OLEJNICZAK ${ }^{4}$, PIOTR JANKOWSKI ${ }^{5}$, ANNA STANISZEWSKA ${ }^{6}$, ARTUR MAMCARZ ${ }^{1}$, and JOLANTA WALUSIAK-SKORUPA ${ }^{3}$}

${ }^{1}$ Medical University of Warsaw, Warsaw, Poland

3rd Department of Internal Medicine and Cardiology

${ }^{2}$ Centre of Postgraduate Medical Education in Warsaw, Warsaw, Poland

School of Public Health

${ }^{3}$ Nofer Institute of Occupational Medicine, Łódź, Poland

Department of Occupational Diseases and Environmental Health

${ }^{4}$ Medical University of Warsaw, Warsaw, Poland

Department of Public Health

${ }^{5}$ Jagiellonian University Medical College, Kraków, Poland

1st Department of Cardiology, Interventional Electrocardiology and Hypertension

${ }^{6}$ Medical University of Warsaw, Warsaw, Poland

Department and Institute of Experimental and Clinical Pharmacology

\begin{abstract}
Long-term exposure to hypercholesterolemia is the cause of atherosclerosis, which in turn causes cardiovascular and cerebrovascular events. In developed countries, including Poland, vascular diseases are the main cause of death. They affect an ever younger part of the population, including the working population. The authors address the problem of epidemiology of cardiovascular diseases, unsatisfactory detection and treatment, economic consequences for the health care system, and the possibilities of using occupational medicine services in the prevention of this health problem. Due to the fact that the early detection of diseases caused by high blood cholesterol levels is relatively low in Poland, obligatory occupational medicine examinations seem to be a key element of the second-line prevention. Therefore, it seems natural to consider the idea of extending the scope of obligatory examinations and introducing tests that allow lipid disorders to be detected at an early stage. This can contribute to a general improvement of the health of the population, and to economic benefits, such as a decrease in the costs of treatment of the disorders that have been detected too late. Broadening the scope of occupational examinations is also important from the perspective of public health and epidemiology of cardiovascular diseases, thus being an element of prevention of civilization diseases. It means improving health and building health awareness, and it should translate into regular health examinations. The performance of these examinations should result not only from the obligation, but also from the patient's conviction about the importance of early detection of disorders, including lipid disorders, for an effective therapy. Int J Occup Med Environ Health. 2019;32(6):865-72
\end{abstract}

Key words:

cardiovascular diseases, occupational health, prophylaxis, hypercholesterolemia, secondary prevention, cholesterol

Received: February 11, 2019. Accepted: August 9, 2019.

Corresponding author: Dominik Olejniczak, Medical University of Warsaw, Department of Public Health, Nielubowicza 5, 02-097 Warsaw, Poland (e-mail: dominik.olejniczak@wum.edu.pl). 


\section{INTRODUCTION}

Cardiovascular diseases (CVDs) are the main cause of death worldwide. According to the World Health Organisation (WHO), about 17 million people die of CVDs annually (49\% of all deaths due to non-communicable diseases). This rate is almost 2 times higher than the mortality rate for cancer, which is the second cause of death in the world. In addition, CVDs are the main cause of premature deaths. Data on the European population in 2012 showed that CVDs caused $38 \%$ and $35 \%$ of deaths among women and men $<75$ years of age, respectively [1].

The epidemiological situation in Poland in 2014 was similar: cardiovascular diseases accounted for $45 \%$ of all deaths (40\% among men, $50 \%$ among women), thus being the first cause of death in the Polish population, preceding cancer. The average was 476 deaths a day, with every fifth death being premature. It is worth noting that CVDs are becoming the main cause of death in the age group $>69$ years [2]. In addition, the NATPOL 2011 study showed that the incidence of elevated low-density lipoprotein cholesterol (LDL-C) was approx. 58\% for both sexes. Improper levels of total cholesterol (TC) and LDL-C have been most frequently found in persons aged 40-59 (> 71\% of respondents); therefore, this age group is considered to be at the highest CVD risk [3].

Data presented in the study of 2016, entitled "Health condition of the Polish population and its determinants," show that Poland is one of the developed countries that are characterized by a high percentage of premature deaths (according to the PYLL index - potential years of life lost), where cardiovascular diseases are the first cause of death among men (26\%), and the second cause of death among women (21\% preceded by cancer $-41 \%$ ).

In addition to being the main cause of death, CVDs are also the main cause of morbidity, hospitalizations, invalidity and sickness absenteeism [4,5]. It should be emphasized that the formation and development of atherosclerotic plaques progress with age, and the pace and type of changes depend heavily on the length and intensity of exposure to risk factors, such as stress, lack of physical activity, or poor diet. The phenomenon of a rapidly aging society seems important in this context, too.

A high level of cholesterol is the most important modifiable risk factor for cardiovascular diseases. Its reduction decreases the risk of cardiovascular diseases in the population. Health intervention in the group at the highest CVD risk, that is the population group aged 40-59, produces the best health effects.

Since 1991, a gradual decrease in CVD mortality has been observed. However, due to these diseases, the life expectancy of the Polish population is still shorter by 3-7 years, compared to the life expectancy in the 15 "old" countries of the European Union [2].

There is no doubt that cardiovascular diseases constitute the main health risk for the Polish population and a great challenge for the Polish health care system. This challenge involves the need to use existing organizational and legal solutions, such as preventive medical examinations of employees. These examinations are performed $>4.5$ million times a year, and each of more than 12.5 million of workers in Poland is obliged to undergo a preventive examination at least once in 4 years [6], which means that the occupational health care system may, and should, be considered an element of public health aimed at the prevention of civilization disorders, which should result in fitness to work being sustained or prolonged.

The risk factors for cardiovascular diseases and their occurrence in the Polish population are presented below.

\section{MAIN RISK FACTORS FOR CARDIOVASCULAR DISEASES}

Cardiovascular diseases are mainly caused by atherosclerosis. The predominant role in etiopathogenesis, development and progression of atherosclerosis is played by modifiable risk factors associated with improper lifestyle (poor diet, too low physical activity, etc.). These risk factors 
may lead to lipid metabolism disorders (hyperlipidemia) or hypertension, which are considered to be the main risk factors for CVDs. A multicenter INTERHEART study, the results of which were included in the WOBASZ (Wieloośrodkowe Ogólnopolskie Badanie Stanu Zdrowia Ludności) study [4], showed that the 2 risk factors mentioned above, nicotine addiction, diabetes, abdominal obesity and psychosocial factors, as well as cardioprotective factors: fruit and vegetable intake, low alcohol consumption and regular physical activity, influenced $90 \%$ and $94 \%$ of cardiovascular events in men and women, respectively. It is worth noting that this relationship was demonstrated in all regions of the world and in all age groups.

A reduction of the risk factors, as the best method of decreasing CVD mortality, has been confirmed in numerous studies around the world, which were presented in the introduction to the WOBASZ analysis. Similar results were obtained in an analysis conducted in Poland in 1991-2005, which showed that a reduction of the risk factors in the population of adult Poles brought about a $54 \%$ decrease in mortality from coronary diseases, whereas improved access to cardiac and cardiac surgery treatment methods resulted in a $37 \%$ reduction in the said mortality. To quote the NATPOL research: "the intensity of CVD factors is one of the most important determinants of life expectancy in Poland" [7].

In order to implement a proper health intervention, it is necessary to know the parameters related to cholesterol concentration in the blood. Currently, detection of cholesterolrelated risks rests mainly with primary care physicians who are usually approached by the patient too late, which significantly delays the cardiologist's intervention. As this situation significantly limits doctors' options, it appears necessary to develop and implement systemic solutions in this area. A person with a significantly increased blood cholesterol level is usually qualified for the statin therapy. However, a problem of not following doctor's instructions can arise.

Another problematic issue is related to persons with slightly increased cholesterol levels, who are not yet quali- fied for the statin therapy. They receive recommendations for a healthy lifestyle (which they often do not follow). The initial lack of symptoms can pose a certain health threat, since the patient leaves the doctor's office with a delusive feeling of being in full health, and often has no motivation to follow the recommendations. Consequently, when the patient visits the doctor again after many years, he/she might already suffer from advanced atherosclerosis, myocardial infarction or stroke. Therefore, the key role of the doctor is to make the patient aware of the health threat. In this respect, obligatory employee medical examinations may prove particularly helpful, as they can help achieve a much higher rate of following medical recommendations among patients, reaching $>90 \%$ [8].

\section{LIPID DISORDERS - GOALS OF TREATMENT}

The most important treatment goal is related to LDL-C, and it depends on the overall cardiovascular risk. Non-high density lipoprotein cholesterol levels can be the secondary goal of therapy, especially in patients with high triglyceride levels. There are no treatment goals for triglycerides due to the lack of evidence from clinical trials that would allow the establishing of such treatment goals. However, the level of $>1.7 \mathrm{mmol} / \mathrm{l}(>150 \mathrm{mg} / \mathrm{dl})$ is considered to be a marker of increased risk. Similarly, although the high density lipoprotein cholesterol level is not the treatment goal, its concentration $<1.0 \mathrm{mmol} / \mathrm{l}(<40 \mathrm{mg} / \mathrm{dl})$ in men and $<1.2 \mathrm{mmol} / \mathrm{l}(<45 \mathrm{mg} / \mathrm{dl})$ in women can be considered a marker of increased risk.

\section{TREATMENT}

It is generally recognized that, regardless of the intervention, a reduction in the LDL-C level by $1 \mathrm{mmol} / \mathrm{l}$ results in a decreased risk of major cardiovascular events by $22 \%$, deaths from the ischemic heart disease by $20 \%$, deaths from vascular causes by $14 \%$, and deaths from all causes mentioned by $10 \%$ [9]. It is worth noting that a drop in LDL-C to very low values (e.g., $0.8 \mathrm{mmol} / \mathrm{l}$ or about 
$30 \mathrm{mg} / \mathrm{dl}$ ) improves the patient's prognosis to a slightly lesser extent than interventions in patients with higher cholesterol levels [10].

\section{EVERYDAY PRACTICE}

Recent studies have shown that although hypercholesterolemia control in the Polish population is gradually improving, it is still not satisfactory. Currently, hypercholesterolemia is effectively controlled only in $6 \%$ of patients (i.e., cholesterol concentration is reduced to the recommended level) [11]. The reason behind this alarming situation is a very high percentage of unrecognized hypercholesterolemia cases, amounting to $61 \%$. Furthermore, $17 \%$ of the patients diagnosed with hypercholesterolemia are not treated. Low hypercholesterolemia control is one of the main reasons for the high incidence of, and mortality from, cardiovascular diseases in Poland, which cause $45.7 \%$ of all deaths [12].

Hypercholesterolemia is not always optimally controlled in the patients after myocardial infarction [13]. Basic prevention goals are often not achieved. One study revealed that, on average, 1 year after hospitalization for acute coronary syndrome or myocardial re-vascularity, only $28.1 \%$ of patients were controlled for hypercholesterolemia (LDL-C $<1.8 \mathrm{mmol} / \mathrm{l}$ ), whereas in $71.9 \%, 38,6 \%, 24.4 \%$ and $10.3 \%$ of patients cholesterol levels amounted to $\geq 1.8 \mathrm{mmol} / \mathrm{l}$, $\geq 2.5 \mathrm{mmol} / \mathrm{l}, \geq 3.0 \mathrm{mmol} / \mathrm{l}$ and $\geq 4.0 \mathrm{mmol} / 1$, respectively [14]. The study showed that the patients' age and the factors related to the organization of the health care system affected the frequency of statin use, while demographic and clinical factors determined the hypercholesterolemia control after hospitalization for the ischemic heart disease. Insufficient hypercholesterolemia control in persons from the highest risk group is one of the causes of high mortality in this group.

\section{SCREENING AND CONTROL TESTS}

Screening tests should be performed in persons with at least 1 risk factor for cardiovascular diseases (e.g., hy- pertension, tobacco addiction syndrome, diabetes, overweight, negative family history), in all men $>40$ years of age and women $>50$ years of age, as well as in patients with cardiovascular diseases, chronic kidney diseases or autoimmune diseases. In the case of a proper lipid profile, it is advisable to repeat the test at least every 3-5 years. Having achieved the target LDL-C level, patients with hypercholesterolemia should repeat the test once a year. It should be emphasized that, in most cases, it is a mistake not to determine the LDL-C level but to measure the total cholesterol level only [15].

Most cases of hypercholesterolemia in Poland remain undiagnosed: WOBASZ II research shows that up to $61 \%$ of persons with hypercholesterolemia are not aware of the disease. This explains the low percentage of hypercholesterolemia control and the fact that only $6 \%$ of persons with hypercholesterolemia are successfully treated.

\section{RELATIONSHIP BETWEEN DYSLIPIDEMIA AND ECONOMIC FACTORS}

The total cost of prevention depends on many factors, including whether it is calculated for a healthy or ill person, a person at risk or not, the type of intervention applied for a particular person, the country of analysis, and the reimbursement for a given medical procedure. The use of generic drugs can significantly affect cost efficiency [16], whereas the costs of laboratory tests in different regions of the same country can significantly change the total costs of prevention. The WHO is of the opinion that political and environmental changes could result in a reduction of the costs of cardiovascular diseases in all countries to $<1 \mathrm{USD} /$ person/year [17]. In addition, data from the United Kingdom show that decreasing the cardiovascular risk by $1 \%$ could prevent 25000 cases of cardiovascular diseases, and bring financial benefits in the amount of 40 million EUR/year [18].

Analyzes of KPMG showed that the total cost of CVD diagnosis and treatment in 2011 amounted to PLN 15.3 bil- 
lion, including hospitalization costs of PLN 7.5 billion, the costs of outpatient care of PLN 3.7 billion, and the costs of pharmaceutical drugs of PLN 4.1 billion. Indirect costs were much higher, amounting to PLN 26.6 billion annually, of which PLN 16.6 billion were allocated to early pensions and retirement pensions, PLN 8 billion were losses resulting from premature mortality, and PLN 2 billion were the costs of sick leaves [19].

In 2013, expenditure on benefits related to the incapacity for work was at the level of PLN 32276.1 million, which was $6 \%$ more than in 2012. Expenses on the incapacity for work pensions constituted the highest percentage and amounted to $48.5 \%$, whereas expenses related to absenteeism from work amounted to $41.3 \%$. Other expenses covered the costs of social pensions $(5.9 \%)$, the costs of rehabilitation benefits (3.8\%), and the costs of medical rehabilitation in the framework of pension prevention of the Social Insurance Institution ( $0.5 \%)$.

Cardiovascular diseases (ICD-10: I00-I99) generated the second highest costs in 2013, accounting for $14.5 \%$ of all costs, and they were preceded only by mental and behavior disorders (ICD-10: F00-F99), which generated 16.8\% of costs. Considering patients' sex and incapacity for work, the highest costs were generated by men with cardiovascular diseases (20.5\%). When calculating expenditure on the incapacity for work in 2013, the expenditure ratio per person covered by health insurance was measured, and it amounted to PLN 198.38 for cardiovascular diseases.

Although studies conducted on the basis of evidencebased medicine are not reliable enough, it can be assumed that expenses on preventive activities are much lower than the costs of complex diagnostic procedures and treatment, of both conservative and invasive nature. It should be emphasized that the prophylaxis of cardiovascular diseases can produce much better results than therapy, while incurring much lower costs. Mortality due to cardiovascular diseases can be reduced by $45-75 \%$ with the use of preventive measures reducing the intensity of risk factors, and by $25-55 \%$ with the use of various means of therapy [20]. Systematic preventive examinations can help detect the disease in its initial phase, as well as prevent the disease progression and its negative consequences. They can not only influence the health of the population, but also bring measurable economic benefits.

In the light of the above, besides the identification and treatment of persons at a high cardiovascular risk, it is of much importance to detect lipid disorders in their early phase, and to provide professional medical counseling. According to the European Society of Cardiology (ESC) and the European Atherosclerosis Society (EAS) guidelines of 2016, effective protective interventions in the early stage of the disease, which are performed in the group of persons at a moderate risk, can prevent a further increase in the total cardiovascular risk, raise the awareness of the threats related to the increased cardiovascular risk, improve the flow of information on the CVD risk, and promote primary prevention activities [21].

\section{PREVENTIVE MEDICAL EXAMINATIONS OF EMPLOYEES}

The negative situation in the field of the diagnosis and control of hypercholesterolemia in Poland could be improved through the implementation of lipid profile tests, as part of pre-employment and routine preventive medical examinations of employees. Preventive examinations are performed in accordance with the Regulation of the Minister of Health and Social Care of 30 May 1996 [22]. Determination of the cholesterol level is obligatory if a job position is related to adverse psychosocial factors (risks resulting from a constant influx of information and readiness to respond, making decisions, responsibility, and life-threatening hazards) and occupational toxic agents (carbon disulfide). However, this solution has certain limitations:

- determination of the cholesterol level is obligatory during the pre-employment and routine examinations, only for those workers who have received from their 
employer a referral with the indication of the above mentioned adverse occupational factors, which are listed in the regulation mentioned above;

- according to the current practice of determining the occupational risk, which at the same time implies the scope of additional examinations (including cholesterol level determination), adverse psychosocial factors are mainly associated with decision-making job positions. However, changes in the nature of work and current expectations towards an increasing number of employees are related to the exposure to professional stress resulting from time pressure and requirements that are often not adjusted to physical or intellectual capabilities of an employee. Therefore, it can be assumed that the number of persons undergoing obligatory cholesterol tests is lower than it is needed;

- it is a standard and common procedure to determine only the total level of cholesterol, whereas performing the full lipid profile requires the approval of the employer who finances the medical examination.

It seems that extensive preventive medical examinations in the framework of preventive activities of occupational medicine should become an effective element of early detection and treatment of dyslipidemia. In Poland, only some employers decide to finance additional pro-health activities. Prophylactic programs aimed at dyslipidemia and cardiovascular diseases comprise 3 areas:

1. Controlling risk factors by health promotion programs oriented towards healthy diet, physical activity, body mass control, and smoke-free environment.

2. Providing additional health care plans and packages covering laboratory tests and access to medical specialists.

3. Financing additional screening tests performed during occupational health check-ups, e.g., the lipid profile or glucose level, not included in the obligatory scope of tests.

These activities lack cooperation with occupational health care. However, an integrated health program should be developed on the basis of the results of tests carried out by a physician providing preventive care to the patient, and be individually adapted to the needs of the employee. There is a difference between the needs of a population in a production plant with the majority of workers aged $>50$ suffering from cardiovascular diseases or being at risk of these diseases, and a group of young employees of a bank, burdened primarily with psychosocial factors. Health activities should be based on the results of scientific research and be preceded by certain arrangements between the occupational physician and the employer. The effects of such activities require constant monitoring and appropriate interventions. Changes in the labor market, the development of technology, including digitization, the prevalence of psychosocial burden, and an increase in the frequency of civilization diseases require the development of integrated models supporting health and productivity. Such initiatives call for financial support from the employer and a good cooperation with occupational health services. Public participation may be an alternative to the above solutions; thus, it seems that occupational health services should be included in performing the prophylactic programs financed by the National Health Fund or the Ministry of Health, as well as regional EU programs or incapacity pension prevention measures funded by the Social Insurance Institution.

Advantage should be taken of the obligatory character of health check-ups of all employees, which gives full participation in the enrolment into a prophylactic program. So, the possible step-by-step procedure is as follows:

- during an obligatory employee's examination financed by the employer, a lipid profile blood test, funded by public institutions, is additionally performed;

- based on laboratory results and medical examinations, the patient is given full information and further advice on modifications in his/her lifestyle, diet, etc., and/or on the necessity to continue diagnostics/treatment in a primary health care unit; 
- the lipid profile is evaluated regularly (every 3-5 years or as required), but not at every health check-up, which may be monitored with the use of an IT system.

\section{SUMMARY}

The most common factor for the occurrence of cardiovascular diseases is dyslipidemia. Lipid disorders, which can lead to the development of atherosclerosis, affect 18 million Poles. Vascular complications, which are a natural consequence of a long-term exposure to hypercholesterolemia, are becoming a problem not only for the patient but also for the health care system. The costs of treatment of cardiovascular diseases are very high. Therefore, it seems justified to conduct extensive educational campaigns for early diagnosis of lipid disorders, and other social activities in the field of primary prevention, which can be of fundamental importance for the reduction of mortality from cardiovascular diseases. Systematic preventive health examinations from an early age could contribute to the detection of diseases at an early stage, and thus reduce morbidity and mortality related to the occurrence of cardiovascular diseases, and lower the costs of treatment and rehabilitation of patients. The implementation of consistent activities in the field of first-, second- and third-line prevention, as part of preventive care for workers, should be an additional element in the early detection and treatment of dyslipidemia. The effectiveness of these activities will depend both on the involvement of the occupational health care system and employers' readiness to finance additional pro-health activities for their workers, as well as on public institutions' support.

\section{REFERENCES}

1. Nichols M, Townsend N, Luengo-Fernandez R, Leal J, Gray A, Scarborough P, et al. European Cardiovascular Disease Statistics 2012 Edition. Brussels: European Heart Network, European Society of Cardiology; 2012.
2. Goryński P, Wojtyniak B. [The health situation of the Polish population and its determinants]. Warsaw: National Institute of Hygiene; 2016. Polish.

3. Zdrojewski T, Solnica B, Cybulska B, Bandosz P, Rutkowski M, Stokwiszewski J, et al. Prevalence of lipid abnormalities in Poland. The NATPOL 2011 survey. Kardiol Pol. 2016; 74(3):213-23, https://doi.org/10.5603/KP.2016.0029.

4. Broda G, Rywik S. [A multi-center nationwide survey of the state of health of the population - a WOBASZ project]. Kardiol Pol. 2005;63:6(supp. 4):S601-4. Polish.

5. Karczewicz E, Sikora A. [Sickness absence in 2017]. Warsaw: The Polish Social Insurance Institution; 2018. Polish.

6. Marcinkiewicz A, Wojda M, Walusiak-Skorupa J, Hanke W, Rydzyński K. Analysis of tasks of occupational health services accomplished in Poland, 1997-2014. Do we exploit the full potential of prophylactic examinations of workers? Med Pr. 2017;68(1):105-19, https://doi.org/10.13075/mp.5893.00509.

7. Lewington S, Whitlock G, Clarke R, Sherliker P, Emberson J, Halsey J, et al. Blood cholesterol and vascular mortality by age, sex, and blood pressure: a meta-analysis of individual data from 61 prospective studies with 55,000 vascular deaths. Lancet. 2007;370:1829-39, https://doi.org/10.1016/ S0140-6736(07)61778-4.

8. Marcinkiewicz A, Plewka M, Hanke W, Kałużny P, Wiszniewska M, Lipińska-Ojrzanowska A, et al. Is it possible to improve compliance in hypertension and reduce therapeutic inertia of physicians by mandatory periodical examinations of workers? Kardiol Pol. 2018,76(3):554-9, https:// doi.org/10.5603/KP.a2017.0250.

9. Baigent C, Blackwell L, Emberson J, Holland LE, Reith C, Bhala N, et al. Efficacy and safety of more intensive lowering of LDL cholesterol: a meta-analysis of data from 170,000 participants in 26 randomised trials. Lancet. 2010;376:167081, https://doi.org/10.1016/S0140-6736(10)61350-5.

10. Sabatine MS, Giugliano RP, Keech AC, Honarpour N, Wiviott SD, Murphy SA, et al. Evolocumab and Clinical Outcomes in Patients with Cardiovascular Disease. N Engl J Med. 2017;376:1713-22, https://doi.org/10.1056/NEJMoa1615664. 
11. Pająk A, Szafraniec K, Polak M, Polakowska M, Kozela M, Piotrowski W, et al. Changes in the prevalence, treatment, and control of hypercholesterolemia and other dyslipidemias over 10 years in Poland: the WOBASZ study. Pol Arch Med Wewn. 2016;126:642-52, https://doi.org/10.5114/ aoms.2017.72423.

12. Rozkrut D. [Demographic Yearbook of Poland 2017]. Warsaw: Central Statistical Office; 2017. Polish.

13. Jankowski P, Czarnecka D, Wolfshaut-Wolak R, Łysek R, Łukaszewska A, Bogacki, et al. Secondary prevention of coronary artery disease in contemporary clinical practice. Cardiol J. 2015;22:219-26, https://doi.org/10.5603/CJ.a2014. 0066.

14. Jankowski P, Czarnecka D, Łukaszewska A, Łysek R, Wolfshaut-Wolak R, Bogacki P, et al. Factors related to the effectiveness of hypercholesterolemia treatment following hospitalization for coronary artery disease. Pol Arch Med Wewn. 2016;126(6):388-94, https://doi.org/10.20452/pamw.3447.

15. Banach M, Jankowski P, Jóźwiak J, Cybulska B, Windak A, Guzik T, et al. PoLA/CFPiP/PCS Guidelines for the Management of Dyslipidaemias for Family Physicians 2016. Arch Med Sci. 2017;13(1):1-45, https://doi.org/10.5114/aoms. 2017.64712 .

16. Plans-Rubio P. The cost effectiveness of statin therapies in Spain in 2010, after the introduction of generics and reference prices. Am J Cardiovasc Drugs. 2010;10(6):369-82, https://doi.org/10.2165/11539150-000000000-00000.

17. World Health Organization [Internet]. Geneva: The Organization; 2011 [cited 2019 Jan 7]. Scaling up action against noncommunicable diseases: how much will it cost? Available from: https://www.who.int/nmh/publications/cost_of_inaction/en/.

18. Collins M, Mason H, O'Flaherty M, Guzman-Castillo M, Critchley J, Capewell S. An economic evaluation of salt reduction policies to reduce coronary heart disease in England: a policy modeling study. Value Health. 2014;17(5):51724, https://doi.org/10.1371/journal.pone.0084445.

19. Strzelecki Z, Szymborski J, editors. Morbidity and mortality of cardiovascular diseases and the demographic situation of Poland [Internet]. Warsaw: Government Population Council; 2015 [cited 2019 Jan 7]. Available from: https://bip.stat. gov.pl/files/gfx/bip/pl/zamowieniapubliczne/426/248/1/81_ gp_rrl_2015_monografia_kardiologiczna.pdf. Polish.

20. Sobieszczańska M, editor. [Prevention of cardiovascular diseases] [Internet]. Jelenia Góra: State College of Karkonosze in city of Jelenia Góra; 2011 [cited 2019 Jan 26]. Available from: https://docplayer.pl/19390733-Prewencja-chorob-sercowo-naczyniowych.html. Polish.

21. Catapano AL, Graham I, De Backer G, Wiklund O, Chapman MJ, Drexel H, et al. 2016 ESC/EAS Guidelines for the Management of Dyslipidaemias: The Task Force for the Management of Dyslipidaemias of the European Society of Cardiology (ESC) and European Atherosclerosis Society (EAS). Atherosclerosis. 2016;253:281-344, https://doi. org/10.1016/j.atherosclerosis.2016.08.018.

22. [Regulation of the Minister of Health and Social Care of 30 May 1996 on the medical examinations of employees, the scope of occupational preventive health care and medical certifications for purposes of the Labour Code. J Laws 2016, item 2067]. Polish.

This work is available in Open Access model and licensed under a Creative Commons Attribution-NonCommercial 3.0 Poland License - http://creativecommons.org/ licenses/by-nc/3.0/pl/deed.en. 